\section{Accesibilidad universal: sentido normativo e implicaciones en la educación y la práctica profesional}

\author{
Universal accessibility: normative sense \\ and implications in education and the \\ professional practice
}

\section{Resumen}

En la Convención sobre los

Derechos de las Personas con

Discapacidad, aprobada por la

ONU en 2006, se incluye el derecho

a la accesibilidad universal y el

diseño para todas las personas.

En este trabajo nos ocupamos, en primer lugar, de clarificar el sentido normativo que tiene este derecho.

Posteriormente, analizamos sus implicaciones en el ámbito de la ética de las profesiones, mostrando la responsabilidad de los profesionales en el diseño de un espacio social diverso y común. Finalmente, analizamos las implicaciones en la educación universitaria que ha de preparar a los profesionales para realizar tal diseño.

\section{Palabras clave}

Accesibilidad universal, diseño para todas las personas, ética de las profesiones, diversidad funcional, educación universitaria.

\begin{abstract}
The Convention on the Rights of Persons with Disabilities, adopted by the UN in 2006, includes the right to universal accessibility and design for everyone. This paper aims to, in the first place, to clarify the normative sense of this right. Subsequently, we analyze its implications in the field of ethics of professions, showing the responsibility of professionals in the design of a diverse and common social space. Finally, we discuss the implications of these results for higher education.
\end{abstract}

\section{Keywords}

Universal accessibility, design for all, professional ethics, functional diversity, university education.

\section{Manuel Aparicio Payá \\ <maparici2@yahoo.es>}

Profesor de Filosofía en el IES Aljada, Puente Tocinos (Murcia)

\section{Emilio Martínez Navarro <emimarti@um.es>}

Universidad de Murcia
Para citar:

Aparicio, M. y Martínez Navarro, E. (20I7): "Accesibilidad universal: sentido normativo e implicaciones en la educación y la práctica profesional”. Revista Española de Discapacidad, 5 (I): 25-4I.

Doi: <https://doi.org/IO.5569/23405 I04.05.01.02>

Fecha de recepción: 02-09-20I6 Fecha de aceptación: 24-OI-20I7 


\section{Introducción}

Uno de los aspectos más relevantes incluidos en la Convención de la ONU de 2006, dedicada a proclamar los derechos humanos de las personas con diversidad funcional, es la cuestión de la accesibilidad universal ${ }^{\mathrm{T}}$. La adecuada comprensión de este derecho humano no puede desligarse del hecho de que en dicho documento jurídico internacional se refleja la influencia del modelo social de la discapacidad (Palacios, 2008). Esta concepción viene a cuestionar una idea comúnmente admitida: que la falta de participación social de las personas con diversidad funcional obedece a causas naturales. Por el contrario, este paradigma pone de manifiesto que este hecho se produce debido a la falta de apoyo a sus vidas y a la existencia de numerosos obstáculos sociales que las discriminan respecto al modo en que se trata al resto de los ciudadanos (Palacios, 2008: I23). Así pues, desde esta concepción se entiende que la accesibilidad universal constituye, fundamentalmente, una cuestión de índole moral-política, ya que busca la reafirmación de la dignidad de tales personas y su plena inclusión como ciudadanos en un espacio social común (Etxeberría, 2005: I06). No obstante, tampoco puede olvidarse que la accesibilidad universal cuenta también con una dimensión técnico-estratégica, puesto que el ejercicio de este derecho requiere del diseño universal o diseño para todas las personas ${ }^{2}$, entendiendo por tal (Bariffi et al., 2008: 33 ) el conjunto de orientaciones para que los diseñadores se esmeren en conseguir incorporar al producto, servicio o entorno aquellas características que lo conviertan en útil para todas las personas o, al menos, para el mayor número posible. Estas cuestiones también se están incorporando en nuestro país en el ámbito de la enseñanza

I. Art. 9 de la Convención de la ONU de 2006. 2. En el art. 2 de la Convención de la ONU de 2006 se define el diseño universal como "el diseño de productos, entornos, programas y servicios que puedan utilizar todas las personas, en la mayor medida posible, sin necesidad de adaptación ni diseño especializado". Se especifica también que no se excluyen diseños específicos cuando las circunstancias personales lo exijan. universitaria, encargada de la formación de profesionales responsables en distintos campos, como un paso más para profundizar en las transformaciones del espacio social para el logro de una sociedad más inclusiva y más justa.

En una época en la que aflora con fuerza el hecho de la diversidad humana, se lanza un importante desafío al conjunto de las profesiones, centradas hasta ahora básicamente en el empleo de normas estandarizadas para atender las necesidades típicas de los usuarios considerados normales. Así pues, el reto al que se enfrentan los profesionales en su formación y en el ejercicio profesional no queda circunscrito al terreno meramente técnico. El compromiso con las personas usuarias, en la diversidad que manifiestan, pertenece también al terreno ético, que afecta a las actitudes morales y a la ética profesional. Tal desafío tiene un correlato claro: la educación universitaria que ha de proporcionarse a los futuros profesionales debe incluir entre sus objetivos tanto la preparación para el diseño de un espacio social común y diverso, como la adecuada formación para convivir en él, respetando la igual dignidad de todas las personas. Afrontar con éxito tales retos exige una revisión de la formación que se está impartiendo a quienes aspiran a un futuro profesional, así como la revisión del ethos (carácter configurado por repetición de actos) profesional. Se trata de adecuarlos a la altura de un tiempo marcado por un derecho universalista y una conciencia moral post-convencional, los cuales exigen el respeto a la autonomía de cada persona y el acogimiento, en aquello que sea justo, de la diversidad que esta demanda.

En este trabajo nos ocuparemos de (I) clarificar el aspecto normativo de la accesibilidad universal y el diseño para todos. Posteriormente, (2) trataremos de justificar que la accesibilidad universal constituye un compromiso ético para el conjunto de las profesiones. Finalmente, (3) analizaremos las implicaciones de este compromiso para la educación de los futuros profesionales en el marco universitario. 


\section{La accesibilidad universal como cuestión ético-política}

Tradicionalmente, se venía entendiendo por accesibilidad universal (De Asís, 20I3) la eliminación de cualquier obstáculo (físico, ambiental, cultural, psicológico o cognitivo) que impidiera o dificultara a la persona con diversidad funcional $-\mathrm{y}$ a otros grupos de personas - su inclusión social. Más recientemente, el concepto ha evolucionado hasta hacer referencia a "aquella condición que deben cumplir los entornos, procesos, bienes, productos y servicios, así como los objetos, o instrumentos, herramientas o dispositivos para ser comprensibles, utilizables y practicables por todas las personas” (Arjona Jiménez, 20I 5: 30).

Los diferentes ámbitos de accesibilidad (Bariffi et al., 2008: 32-33), relacionados con el uso y disfrute de los derechos, abarcan una amplia variedad de aspectos de la vida social: a) La movilidad en el entorno material: diseño urbano, edificación, uso de los transportes, apoyo a la movilidad, etc.; b) La comunicación y la información: acceso a los medios de comunicación, uso de lenguajes alternativos, comprensión de la información, acceso a las nuevas tecnologías de la información y la comunicación, etc.; c) Los bienes y servicios: educación, sanidad, servicios sociales, ocio y turismo, etc.; d) Concienciación social (Etxeberría, 2008: 40): no discriminación, eliminación de prejuicios, etc.

¿Cuál es el significado ético-político de la accesibilidad universal? Para responder a esta pregunta hemos de caer en la cuenta de que el diseño y la puesta en práctica de cualquier proyecto personal de la propia vida, en sus múltiples facetas, necesita del apoyo del espacio social en el que se inserta la persona. No hay, por tanto, una autonomía personal -en ningún ser humano- que sea autosuficiente; lo que hay es una autonomía construida desde la interdependencia. La vida del individuo, al menos en cierta parte, depende del diseño existente en el espacio social, formado por un entorno material (vías públicas, edificios, medios de transporte, comunicaciones, etc.) y por componentes inmateriales (ideas, valores, actitudes, expectativas, etc., de quienes rodean al individuo). Estos últimos tienen una influencia decisiva en la configuración que adopta el entorno material. La repercusión que tiene dicho diseño en el plan de vida de cada persona dependerá de las condiciones sociales (materiales e inmateriales) que se proporcionen a quienes se desenvuelven en él. Tradicionalmente, el entorno social estuvo diseñado sin atender a la inclusión, considerando únicamente las necesidades típicas de los ciudadanos considerados normales (Nussbaum, 2007). Mientras que se proporcionaba a la mayoría de ciudadanos condiciones adecuadas de acceso al entorno social, los ciudadanos con otro tipo de necesidades corporales y mentales carecían de ellas. Por tanto, son las diferencias en las condiciones proporcionadas ${ }^{3}$ para el acceso al entorno social la clave de la exclusión de la minoría.

La idea normativa de accesibilidad universal, con los valores de solidaridad e inclusión que encierra, tiene conexión con la idea de no discriminación de grupos sociales minoritarios. Se apoya, por tanto, en el principio de igual trato jurídico, surgido con la aparición del derecho moderno. Este principio se sustenta, a su vez, en el principio moral de igual dignidad de todos los seres humanos. En último término, la idea de accesibilidad universal viene a significar el "derecho a ser tratado como un ciudadano" (Nussbaum, 2006: 353 ) y, en sentido cosmopolita, el derecho a ser tratado como ser humano. El derecho humano a la accesibilidad universal, introducido en la Convención de 2006, pone de manifiesto que, cuando se proporcionan iguales condiciones de acceso al conjunto de los derechos, se está buscando una equitativa igualdad de oportunidades, orientada a la participación en las diferentes dimensiones de la vida social. Este derecho se aleja de un universalismo abstracto y homogeneizador; proyecta, más bien, un universalismo respetuoso con la diferencia (Habermas, 2008).

3. Art. 9 de la Convención de 2006. 
Por otra parte, cabe preguntarse por el sentido normativo que tiene el derecho humano a la accesibilidad universal. Lo que está en juego con este derecho es la posibilidad de ejercer el conjunto de los derechos humanos (civiles, políticos, económicos, sociales y culturales) propios de todas y cada una de las personas, así como el disfrute de los bienes y servicios producidos socialmente, derivados de tales derechos. Para conseguirlo, debe crearse un espacio social facilitador (Nussbaum, 2006) para todas las personas que vivan en él, construyendo una ciudadanía incluyente en el conjunto de sus dimensiones (civil, política, social, económica, cultural, cosmopolita) (Cortina, 2005a). Si el reconocimiento del conjunto de los derechos humanos cobra sentido como condición de la autonomía personal privada y pública (Honneth, 20I4), entonces puede decirse que el sentido normativo de la accesibilidad universal, en tanto que esta constituye una condición-puente hacia el ejercicio del conjunto de los derechos humanos, radica en favorecer el ejercicio de la autonomía personal - hasta donde lo permitan las circunstancias individuales -, protegiendo a la vez la vulnerabilidad humana - realizada o latente-.

No puede obviarse, por último, que no se construye un puente para quedarse en él, sino que se levanta para usarlo como un medio para evitar detenerse y poder continuar en una dirección determinada. La dirección normativa a la que apunta la accesibilidad universal es permitir el acceso a unos derechos que garanticen a todos los seres humanos el disfrute - al menos en un mínimo decentede los bienes de justicia (alimento, vivienda, trabajo, educación, desplazamiento, cultura, etc.) (Cortina, 2005c: I65-I68), si es que ha de seguir teniendo sentido favorecer la autonomía personal y proteger la vulnerabilidad humana. Garantizar dichos bienes de justicia dependerá, como ya defendiera Kant ( I980), de que se siga reconociendo el igual valor de toda persona, por encima de todo precio.

\section{La accesibilidad universal y el mundo de las profesiones}

Podemos preguntarnos a quién corresponde la responsabilidad en la creación de un espacio social accesible para todos los ciudadanos ${ }^{4}$. La respuesta a este interrogante es que dicha tarea corresponde al conjunto de los ciudadanos, agrupados como están en una comunidad que cuenta con un entramado institucional del que forman parte el Estado, las empresas y las entidades de la sociedad civil. No trataremos ahora de justificar esta afirmación, lo que conllevaría también diferenciar las responsabilidades concretas de cada uno de los componentes del entramado social. En este trabajo nos ocupamos únicamente de la responsabilidad que corresponde al mundo de las profesiones. Entonces la cuestión será: ¿qué deben hacer responsablemente los profesionales para apoyar este derecho humano? Para responder a este interrogante, tendremos en cuenta dos puntos de vista, conectados entre sí:

I. Si se consideran (Habermas, 2000: I IOI 2I) los diferentes tipos de cuestiones prácticas existentes (pragmáticas, éticas y morales), se podría responder que:

a. Desde un punto de vista pragmático, las diferentes profesiones deben ocuparse de los medios técnicos y de las estrategias convenientes con el fin de satisfacer las necesidades humanas. Esta perspectiva tecno-estratégica se refiere a las posibilidades de innovación en los diferentes ámbitos de accesibilidad. En tal caso, lo que debe hacer el profesional es esforzarse por contar con una formación actualizada que contribuya a desarrollar aquellas habilidades pragmáticas que le capaciten para lograr tal fin. No obstante, aunque esto constituye una condición necesaria, no es una

4. Empleamos el término ciudadano para referirnos a toda persona que vive en un espacio social, independientemente de que tenga o no reconocida la ciudadanía. 
condición suficiente. En tal sentido, se ha señalado (Quintanilla, I995: 207) que la innovación técnica no responde tan claramente al esquema lineal necesidad-conocimiento disponiblediseño técnico; en realidad, puede verse frenada si no cuenta con el apoyo de la sociedad y la implicación de los sectores económicos, cuyos intereses no siempre coinciden con la puesta en práctica de tal derecho.

b. Por otra parte, la labor profesional no se reduce al despliegue de un conjunto de habilidades: detrás de ellas está la persona que elige y practica una profesión. Una profesión también constituye un proyecto personal (Martínez Navarro, 2006) dirigido a conseguir una vida lograda. Lo cual depende, a su vez, de quién es y quién quiere ser una persona, es decir, de su carácter moral. En tal sentido, la persona, a través de su actividad profesional, deberá ir configurando un ethos (carácter) que le haga considerar que es bueno para su autorrealización impulsar buenas prácticas innovadoras, en tanto que estas proporcionarán un bien a otras personas con las cuales convive y a las que presta sus servicios profesionales. No obstante, lo que desde un punto de vista ético un profesional debe hacer no responde únicamente a un interés subjetivo, por muy bienintencionado que este pueda ser; también debe actuar de acuerdo a reglas derivadas de las tradiciones propias de la profesión, de la institución para la que trabaja y del contexto social en el que se desenvuelve, si bien es cierto que estos contextos no siempre están suficientemente atentos a las necesidades de accesibilidad de los grupos minoritarios. Se necesitará, pues, que la legislación, los códigos deontológicos regulatorios del ejercicio profesional y la reflexión ética propia impulsen - buscando puntos de engarce con la tradiciónla innovación en el rediseño de los entornos, servicios, programas o productos que atañen a dicha profesión.

c. Un profesional puede querer hacer también aquello que resulte correcto. En tal caso, el profesional deberá plantearse si las normas que regulan su profesión son justas y si contribuyen al respeto a los derechos humanos de todos los afectados por su ejercicio profesional. Desde esta óptica moral, los profesionales de un determinado campo deberán plantearse revisar lo que se consideran buenas prácticas profesionales en relación a la concreción de la accesibilidad universal. Ahora bien, una adecuada revisión de la profesión en la dirección indicada no puede ser llevada a cabo únicamente por los profesionales, sino que debe incluir también a los usuarios (o, en su caso, a sus representantes) (Martínez Navarro, 20I0: 66). Lo cual se justifica tanto por razones morales, ya que los usuarios son personas que deben ser respetadas en su autonomía y en el derecho que tienen, en tanto que ciudadanos, a ser tenidos en cuenta a la hora de reconfigurar el espacio social, como por razones epistémicas, puesto que así podrán aportar unos conocimientos y unas razones - complementarios al conocimiento y a las razones aportadas por los profesionales expertos - acerca de cómo sus vidas pueden verse obstaculizadas o favorecidas por los distintos entornos, objetos o servicios existentes, históricamente configurados a sus espaldas. Dicha revisión exige que las personas con diversidad funcional, en tanto que personas usuarias de los servicios profesionales, sean reconocidas como interlocutores válidos, y participen en un diálogo civil (Bariffi et al., 2008: 35 ) entre sus representantes, el Estado, las empresas 
y también las distintas corporaciones profesionales. Así pues, el ethos profesional debe configurarse como un ethos dialógico (Cortina, 2005b: 42), contribuyendo así a perfilar normas justas para un rediseño del espacio social respetuoso con la diferencia y que, a la vez, responda a intereses universalizables.

2. Por otra parte, en conexión con lo antes expuesto, puede realizarse un acercamiento a la cuestión de la accesibilidad universal y el diseño para todos teniendo en cuenta los rasgos definitorios y el sentido de una profesión:

A la hora de entender lo que es una profesión pueden adoptarse dos puntos de vista. Puede contemplarse la profesión desde un punto de vista externo, según el cual lo que se busca, en el marco de la división social del trabajo, es el éxito social y los bienes que éste conlleva (dinero, estatus, poder, etc.). Desde esta óptica, se considera que quienes practican una profesión lo que hacen es luchar por el reconocimiento social (Honneth, 2006), compitiendo con los demás profesionales y con las demás profesiones por lograr el máximo posible de tales bienes externos.

No obstante, la profesión puede entenderse también desde el punto de vista de su finalidad interna: teniendo en cuenta los bienes internos (por ejemplo: educación, información, objetos, entornos materiales y virtuales, etc.) que se aportan a la comunidad. Al ser común a todas ellas la consecución de algún bien, la determinación de cada bien interno concreto es lo que nos da la pista para caracterizar a cada una de las profesiones. Desde este punto de vista, prioritario respecto al primero, una profesión (Cortina 2005a: I49-I 53) es una actividad socialmente regulada, mediante la cual quienes la practican (los profesionales) aportan un cierto bien que favorece a los miembros de la comunidad (los usuarios). Como institución social intermedia, una profesión cobra sentido desde su finalidad: teniendo en cuenta los bienes internos que, para satisfacer las necesidades de las personas usuarias, aporta a la comunidad. Desde este punto de vista, cada profesión constituye un servicio indispensable para vivir bien.

Por su parte, Augusto Hortal (2002: 10) la concibe como una actividad ocupacional en la que: a) se presta un servicio específico a la sociedad de forma institucionalizada; b) hay un conjunto de personas (profesionales) que se dedican a ella de forma estable, obteniendo su medio de vida; c) se forma con otros profesionales (colegas) un colectivo que tiene el control monopolístico sobre el ejercicio de la profesión y d) se accede a ella tras un largo proceso de capacitación teórica y práctica.

De acuerdo con esta visión interna de lo que es una profesión, pueden indicarse algunas responsabilidades que habría de asumir un ethos profesional que responda al universalismo abierto a la diferencia subyacente en la demanda social para conseguir la accesibilidad universal y el diseño para todos:

a. El profesional tiene que proporcionar un servicio auténticamente universal, es decir, un servicio que realmente abarque a todas las personas usuarias que están al alcance de su actividad profesional, que puede extenderse desde el nivel local hasta el ámbito global. Con ello, el profesional podrá evitar una práctica profesional deshumanizada (Gómez-Senent, 2000: I46), producida cuando se excluye a personas pertenecientes a grupos estigmatizados y postergados.

b. El profesional ha de prestar un servicio atento a la diversidad humana. El objetivo será que los bienes internos aportados desde el ejercicio profesional puedan satisfacer la diversidad de necesidades humanas, sean estas ampliamente compartidas (necesidades típicas) o propias de grupos sociales minoritarios (necesidades atípicas). 
Como bien señala Nussbaum (2007) las necesidades humanas forman un continuum en el que resulta arbitrario establecer diferenciaciones, por lo cual atender algunas de ellas, desatendiendo otras, resulta también arbitrario y discriminador.

c. El profesional ha de contribuir a favorecer la autonomía personal mediante un servicio que aporte un diseño versátil y ampliamente empoderante, capaz de ofrecer oportunidades a una amplia mayoría de personas, no solo para el disfrute de los derechos (autonomía privada), sino también orientadas, en último término, para la participación en el diseño de la sociedad (autonomía pública). También hay que tener en cuenta que una misma persona puede tener necesidades distintas en distintos momentos de su vida, de forma que si un diseño favorece la versatilidad de usos de entornos, bienes y servicios, entonces permitirá que la misma persona continúe usándolos cuando sus circunstancias varíen y pase a tener necesidades distintas.

d. Se ha de procurar un servicio profesional cuidadoso y empático (Etxeberria, 2005) con el conjunto de usuarios, cuestionando prejuicios y estereotipos que puedan tenerse hacia ciertos colectivos minoritarios. De este modo puede ponerse freno a la estigmatización que pueda interponerse en la calidad del servicio ofrecido y conseguir, a través de la conexión empática, una adecuada comprensión de lo que el usuario necesita, poniendo un mayor cuidado para proporcionarle el bien interno de la profesión.

e. Se realizará un servicio profesional que colabore a difundir una imagen respetuosa y ajustada a la realidad de las personas con diversidad funcional -o de otros grupos minoritarios - . Dicha difusión a los profesionales de diferentes ámbitos y al conjunto de la sociedad tiene un doble objetivo en relación a la accesibilidad universal: por una parte, para que se continúen realizando políticas públicas, apoyadas por los ciudadanos, que profundicen en la accesibilidad y, en segundo lugar, con el fin de que se favorezca un trato respetuoso hacia tales personas, de modo que se proporcione una más efectiva inclusión en el espacio social común construido.

El profesional excelente (Martínez Navarro, 20I0: 62) es aquel que aúna la capacidad técnica requerida para ser un profesional competente, con la capacidad moral necesaria para convertirse en un profesional íntegro. No basta, pues, con asumir una serie de deberes técnicos o estratégicos, sin la adopción de una responsabilidad solidaria con el conjunto de personas usuarias y sin tomar en consideración la configuración de un ethos profesional atento a una aportación auténticamente universal de los bienes internos que dan sentido a la profesión. El profesional excelente habrá de asumir un doble compromiso ético con el conjunto de los ciudadanos y, en último término, con el conjunto de la humanidad (Martínez Navarro, 20I4): ofrecer, por un lado, un servicio diligente que proporcione ayuda a los usuarios y, por otro, un servicio que busque la justicia luchando contra la exclusión social, respetando los derechos humanos y denunciando las injusticias que se cometan con las personas que usan tales servicios. En tal sentido, la ayuda profesional diligente debe proporcionarse también a las personas con diversidad funcional, tomando como referencia última los derechos humanos establecidos en la Convención de 2006.

4. La educación superior ante el reto social de la accesibilidad universal

El desarrollo de buenas prácticas profesionales favorecedoras del reconocimiento del derecho 
a la accesibilidad universal requiere de una previa y adecuada formación profesional que tiene lugar en la educación superior recibida en el ámbito de la universidad. Hay que tener en cuenta, no obstante, que la educación superior se apoya en la educación recibida en etapas previas. Es decir, se trata de una continuación y profundización en un proceso iniciado mucho antes. Así pues, corresponde a la educación universitaria dar continuidad a dicho proceso, adaptándolo a los rasgos psicológicos característicos de la persona adulta.

Lo que caracteriza a la etapa educativa en la que el educando llega a ser adulto e ingresa en la universidad es la especialización que le prepara para ejercer una profesión, bien entendido que esto no excluye la adecuada preparación humana del profesional. Dicha especialización se sustenta en los dos pilares básicos, ligados entre sí, que deben ser aportados por la cultura universitaria: una docencia de calidad, con la que se transmite la tradición de dicha profesión, y una investigación excelente que contribuya a su renovación. La identidad propia de la institución universitaria consiste en (Martínez Navarro, 2010: 246-256) completar la formación del alumnado como profesionales de alto nivel en alguna parcela del saber, pero sin descuidar su formación moral como personas y como ciudadanos, para ofrecer un servicio profesional de calidad a la sociedad y al conjunto de la humanidad. Dicha formación, basada en la tradición de una profesión, está abierta a la innovación surgida de la investigación y de la revisión de los conocimientos. En todo caso, la especialización ha de ser compatible con una formación interdisciplinar, en la medida en que abordar la problemática de construir una sociedad accesible - al igual que ocurre en otros muchos problemas - no es tarea de una única especialidad.

Para poder afrontar adecuadamente el reto formativo que supone la accesibilidad universal, la Conferencia de Rectores de las Universidades Españolas (CRUE), contando con la colaboración de la Fundación ONCE, está desarrollando en los últimos años un proyecto que se va concretando en la elaboración de un conjunto de publicaciones dedicadas a la formación curricular en diseño para todos en los diferentes estudios de grado 5 . El objetivo de tales publicaciones es dar respuesta a la obligación legal ${ }^{6}$ de preparar progresivamente el espacio educativo universitario para llevar a cabo la formación de los futuros profesionales en las tareas de diseño para todas las personas que habrán de desempeñar en sus respectivos campos profesionales. Estamos, ciertamente, ante un proyecto que, más allá de la exigencia legal, encierra una gran relevancia, tanto por su repercusión en el propio mundo académico como por el impacto buscado en orden a la transformación del espacio social común:

a. La introducción de la perspectiva de la diversidad funcional en las diferentes disciplinas académicas tiene, a nuestro juicio, una serie de consecuencias positivas. Dada la similitud que encontramos respecto a lo que Nussbaum (2014: 202) señala refiriéndose a la introducción de los estudios feministas, la primera de ellas sería que, con la incorporación de dicha perspectiva, se abre el camino para la transformación interna de las propias disciplinas, las cuales hasta hace escasas

\footnotetext{
5. Este proyecto comenzó en 2006 con el Libro Blanco del Diseño para Todos en la Universidad. En el curso 200920 Io comenzó la adaptación en los grados de áreas técnicas de conocimiento (Arquitectura, Diseño, Informática y Telecomunicaciones, Ingeniería de Caminos, Canales y Puertos e Ingeniería Industrial). En el curso 20I3-20I4 continuó la adaptación en los grados de ADE, Medicina, Pedagogía, Psicología, Trabajo Social y Derecho. En este curso 20I6-20I7 se han propuesto las adaptaciones de los grados de Ciencias Políticas, Enfermería, Farmacia, Periodismo, Sociología y Terapia Ocupacional. Todas estas adaptaciones están plasmadas en las correspondientes publicaciones bajo el título general de Formación curricular en diseño para todas las personas, realizadas por parte de la CRUE en colaboración con la Fundación ONCE.

6. Esta temática se introduce en la Ley $5 \mathrm{I} / 2003$, de 2 de diciembre, de Igualdad de Oportunidades, No Discriminación y Accesibilidad Universal de las personas con discapacidad (LIONDAU), y en la Ley 49/2007, de 26 de diciembre, de infracciones y sanciones en materia de igualdad de oportunidades, no discriminación y accesibilidad universal de las personas con discapacidad. Posteriormente, el Real Decreto I $393 / 2007$, de 29 de octubre, por el que se establece la ordenación de las enseñanzas universitarias oficiales, promueve la aplicación de la accesibilidad universal y el diseño para todas las personas en el ámbito educativo universitario.
} 
décadas ignoraban o postergaban a este amplio sector minoritario de la población y sus necesidades. Por otra parte, en la medida en que el proyecto abarca, paulatinamente, a un amplio abanico de diferentes estudios de grado (técnicos, científico-naturales, científico-sociales, humanísticos y artísticos), también debe tenerse en cuenta que la transformación interna de las diferentes disciplinas repercutirá, a su vez, en el volumen y la profundidad de los estudios sobre las personas con diversidad funcional. Con tal reequilibrio cognitivo lo que sale ganando es, sin duda, la meta a la que aspira la institución universitaria, en tanto que depositaria del saber: la búsqueda de la verdad.

El proyecto impulsado por la CRUE conlleva, pues, un trasvase académico mutuamente beneficioso entre las diferentes disciplinas y el ámbito interdisciplinar que suponen los estudios sobre diversidad funcional. Esta ganancia en la densidad de dichos estudios facilitará, a su vez, la posterior especialización que caracteriza a los estudios de máster y de doctorado, como los que se plantean sobre accesibilidad universal y diseño para todos. Este doble nivel, tanto el básico de cada grado como el referido a la mayor especialización, resulta de interés: por un lado, porque se ofrece una preparación profesional general a un más amplio número de profesionales que, más tarde, atenderán a las personas con diversidad funcional desde sus respectivas profesiones; por otro, porque también se podrá dar una mayor profundidad a quienes deseen alcanzar una mayor especialización en este campo interdisciplinar.

Una segunda consecuencia académica del proyecto impulsado por la CRUE tiene que ver con la existencia de un enfoque común a todos y cada uno de los diferentes volúmenes publicados. En tales publicaciones encontramos una introducción compartida que proporciona un mismo tronco orientador. Esta parte común hace referencia a un modelo de diseño basado en "la diversidad humana, la inclusión social y la igualdad". Se incorpora, en cierto modo, el modelo social de la discapacidad, que apunta hacia la justicia y las obligaciones ético-jurídicas incluidas en la Convención de 2006. Se pretende, con ello, que la perspectiva ético-política impregne y complemente el conjunto de contenidos incluidos en los correspondientes estudios de grado. En este planteamiento subyace, pues, una concepción académica superadora del mero positivismo, entendiendo que debe establecerse un engarce entre el conocimiento y los valores. Dada la conexión que antes señalábamos entre los derechos humanos y la accesibilidad universal y el diseño para todos, se pone así de manifiesto que las disciplinas académicas, incorporando tales cuestiones, no son axiológicamente neutras; que no deben quedar desligadas de los problemas de justicia existentes en la sociedad sino que, por el contrario, han de contribuir a la construcción de una sociedad más inclusiva y más justa.

b. En lo que respecta a las consecuencias sociales derivadas del proyecto de la CRUE podemos señalar las siguientes:

Una primera consecuencia es la que afecta a la propia institución universitaria. Tal proyecto deja patente, a través de la formación de los futuros profesionales, la responsabilidad social corporativa ${ }^{7}$ de la universidad $^{8}$ en el impulso al cumplimiento

7. Se entiende por responsabilidad social corporativa (RSC), a veces denominada responsabilidad social empresarial (RSE), el modo que tienen las organizaciones y las empresas de gestionar sus impactos en el medio social y ambiental en el que están presentes, gestión que va más allá de lo establecido legalmente. Cfr. Lozano, J. F. (20I I): Qué es la ética de la empresa. Cànoves y Samalús: Proteus.

8. François Vallaeys define la RSU como el "proyecto de promoción social de principios éticos y de desarrollo social equitativo y sostenible, para la producción y transmisión de saberes responsables y la formación de profesionales ciudadanos igualmente responsables”. ¿Qué es la responsabilidad social universitaria? (http://creasfile. uahurtado.cl/RSU.pdf, acceso 26 de diciembre de 2016). Puede consultarse también Vallaeys, F. et al. (2009): Responsabilidad Social Universitaria. Manual de primeros pasos. México D. F.: Banco Interamericano de Desarrollo/ Mc Graw-Hill. 
de los derechos humanos en la vida social. La responsabilidad social universitaria (RSU) en el terreno que nos ocupa conlleva (Observatorio Universidad y Discapacidad, 2OI 2: 52-53): a) garantizar una equitativa igualdad de oportunidades en el conjunto de personas con las que se relaciona (profesores, alumnos, PAS, etc.), alcanzando la plena accesibilidad en sus infraestructuras, productos y servicios; b) la implantación responsable de los cambios curriculares derivados de lo legalmente establecido, c) el fomento de una formación reflexiva que, combinando lo cognitivo y lo valorativo, contribuya a dar a conocer la problemática social vivida por las personas con diversidad funcional y contribuya a la implicación en la búsqueda de soluciones a la misma y d) prestar especial atención a la interacción social, la investigación y el desarrollo de proyectos locales y globales que contribuyan a la accesibilidad universal $y$, en consecuencia, al reforzamiento de los derechos humanos de tales personas.

Una segunda consecuencia tiene que ver con la transformación de las profesiones a la que apunta el citado proyecto. Se trata de reforzar los diferentes servicios profesionales, en tanto que instituciones sociales intermedias, para hacerlos más conscientes de la diversidad humana y que puedan proporcionar bienes y servicios más incluyentes.

Por último, la consecuencia de mayor calado a que se apunta con la potenciación de la accesibilidad universal y el diseño para todas las personas, es la que se refiere a la propia transformación social. No se trata únicamente de una cuestión que afecte a los especialistas formados en la Universidad, sino que, como señala Saskia Sassen (CRUE y Fundación ONCE, 2014: I 5-I6), estamos ante una cuestión que afecta al conjunto de la ciudadanía. Por un lado, tanto los profesionales encargados de la accesibilidad universal, como las personas con diversidad funcional, en tanto que usuarios, son ciudadanos afectados. Por otro lado, el resto de los ciudadanos también son responsables, a través de sus actitudes, de hacer una sociedad más accesible. Se trata, en suma, de un compromiso que busca transformar la sociedad para conseguir hacerla más inclusiva, igualitaria y respetuosa con los derechos humanos de todos.

\section{La formación del ethos profesional}

A continuación nos ocupamos de la cuestión de la formación de un ethos profesional que sería deseable para que la consecuente práctica profesional aborde con cierto éxito aquello que se requiere para el diseño de una sociedad accesible en los diferentes ámbitos. No puede olvidarse que, aunque estamos ante una obligación legal, sigue siendo necesaria una formación ética que respalde e impulse el cumplimiento de la ley.

Tendremos en cuenta que la acción educativa (Ortega, 20Io) es una acción moral, en tanto que incluye no solo atender a un necesario equipamiento intelectual, sino también a un conjunto de valores apropiados a una sociedad pluralista (libertad, igualdad, solidaridad, dignidad de la persona, etc.). También tendremos en cuenta que es una acción política, ya que ha de tener en cuenta el contexto en el que se desenvuelve, que en el mundo actual viene marcado por el auge de la diversidad humana, como ocurre con la puesta de relieve de la problemática social de las personas con diversidad funcional.

Para definir el ethos profesional adecuado nos apoyaremos, como hilo conductor, en dos aportaciones de la profesora Cortina a la hora de definir, en un sentido amplio, lo que es la educación: a) su propuesta de educación cordial y, en conexión con la misma, b) su concepción de la neuroeducación moral.

a. La formación de los diferentes profesionales no debería quedar reducida a la formación 
de técnicos que se limitan al conocimiento de los medios que se han de poner para el logro de ciertos fines; tales profesionales también habrán de conocer y apreciar "los fines, los valores y las excelencias de su actividad profesional" (Cortina, 2016). Ciertamente, como señalábamos más arriba, la problemática de la accesibilidad universal y el diseño para todos no se reduce a una cuestión técnico-estratégica, aunque también la incluye. Es conveniente, desde nuestro punto de vista, que cuando esta cuestión se aborde en los programas formativos universitarios, se haga desde una perspectiva interdisciplinar que incluya, además de los conocimientos técnicos específicos de cada especialidad, un marco global (aspectos históricos, sociales, antropológicos, ético-políticos, etc.) que facilite su comprensión y favorezca la motivación para comprometerse con los valores éticos de justicia social. Esto es necesario también porque las soluciones que se vayan avanzando sobre dicha problemática requerirán, como ha ido ocurriendo hasta ahora en este y en otros problemas sociales, de aportaciones interdisciplinares en las que habrán de colaborar profesionales de diferentes áreas de conocimiento. Un aspecto fundamental que, a nuestro juicio, no debe faltar en dicho marco global es la dimensión ético-política. Porque la cuestión de la accesibilidad universal constituye una cuestión de justicia con las personas con diversidad funcional, relacionada con el cumplimiento de los derechos humanos recogidos en la Convención de 2006, cuya solución concierne al marco político de la democracia deliberativa. Y, en segundo lugar, como señalamos en el apartado 2, porque uno de los ámbitos de la accesibilidad es la propia concienciación social para evitar los prejuicios y el trato discriminatorio hacia dichas personas.

Para forjar el ethos profesional, es necesario tener en cuenta los tres ejes fundamentales de una educación moral, entendida en un sentido amplio (Cortina, 2009a: 253-263):
I. Un primer nivel de formación del ethos profesional es el que corresponde a la adquisición de habilidades (pragmáticas, de pensamiento, comunicativas, etc.) y de conocimientos en un campo profesional concreto. Se tratará, pues, de conseguir un ethos profesional bien informado y habilidoso. Sin una preparación adecuada en este terreno no podría realizarse con éxito el servicio profesional que busca satisfacer los intereses de los usuarios. No puede realizarse ningún tipo de diseño, en relación con algún tipo de problema que tenga la sociedad, si no se dispone de las habilidades y los conocimientos adecuados que permitan plantear diversas alternativas realizables. Por eso mismo, aunque la mejora de la accesibilidad universal sea un objetivo moralmente deseable, no podrá realizarse sin contar con conocimientos pertinentes para diseñar alternativas técnicamente viables ${ }^{9}$.

También son necesarias habilidades comunicativas y deliberativas para trasladar tales diseños - al menos aquellos que impliquen una dimensión macroscópica - a la esfera de la opinión pública, encargada de determinar, mediante la deliberación, si el diseño presentado es justo o no (en tanto que responde a razones que encierran intereses universalizables); y también para trasladarlo ante los que tienen poder, para tomar la decisión de llevar dicho diseño a la práctica. Tampoco podemos olvidar que quienes tienen poder decisorio, en muchos casos, cuentan con una formación universitaria, lo que refuerza la responsabilidad de la universidad con la resolución de

9. En tal sentido, el filósofo de la ciencia Nicholas Rescher (I999: I05) considera que el conocimiento es un aspecto importante del bien, que sirve para realizar con eficacia cualquier otro bien legítimo que pueda plantearse. En la medida en que el conocimiento responde al cómo y al por qué, podrán diseñarse alternativas eficaces y eficientes para alcanzar el fin valioso de mejorar la accesibilidad. 
problemas sociales de cada momento (Martínez Navarro, 2010: 255).

2. Lo importante a la hora de determinar la bondad de los medios técnicoestratégicos es el fin perseguido y la valoración de la relación mediosfines corresponde a la prudencia. El profesional (y, por su formación, los gobernantes entre ellos) ha de adquirir una formación adecuada para ser prudente, es decir, para saber lo que conviene, individual y socialmente, en lo que se refiere a lograr una vida de calidad. A ello contribuyen también las habilidades sociales que puedan adquirirse.

De esta formación en la prudencia depende un uso sostenible de los recursos naturales, un uso eficaz y eficiente de los recursos económicos, pero también la valoración positiva de la cooperación con otros ciudadanos para alcanzar metas comunes y apostar por un diseño accesible del que también podrá beneficiarse el propio diseñador (o diseñadores). Este ethos profesional prudente es el que podrá hacer que el profesional considere que el bien que persigue, la autorrealización, ha de incluir el bien de otros miembros de la comunidad.

3. Sin embargo, no basta con educar en la prudencia para atender a las demandas justas que provienen de la sociedad. Es necesario educar el sentido de la justicia, cuyo desarrollo es necesario para que no se frenen aquellas demandas de justicia ni se excluya a ciertos grupos sociales cuando puede verse que podría salir perjudicado el bienestar de uno mismo. Tal sentido de justicia es el que tiene que reconocer los bienes de justicia (protección social, educación, accesibilidad, etc.) recogidos en la Convención de 2006, que los seres humanos con diversidad funcional necesitan - al menos en un mínimo - para tener una vida digna.
Pero también el ethos profesional ha de contar con el sentido de gratuidad que aporte bienes que no son exigibles, pero sin los que la vida humana sufriría una grave pérdida (es, por ejemplo, el que fomenta acciones solidarias, en las que se comparte el tiempo y los conocimientos adquiridos para ayudar a quienes más lo necesitan). Ambos sentidos contribuyen a degustar aquello que es el valor fundamental: la dignidad de la persona. En ese sentido, el ethos profesional cobra sentido último desde un servicio a la dignidad de toda persona que sea respetuoso con los derechos humanos.

Si hacemos un pequeño balance, la propuesta de la profesora Cortina para la formación universitaria del ethos profesional tiene relevancia y suma pertinencia en el tema que nos ocupa, ya que su concepción amplia de la educación pone de manifiesto la necesidad de formar profesionales que faciliten el empoderamiento de las personas y se comprometan con la vulnerabilidad humana. Su propuesta de educación moral (que incluye la configuración de un ethos profesional informado y habilidoso, prudente y con sentido de justicia y gratuidad) facilitará que pueda darse un servicio profesional a las personas usuarias ampliamente empoderante y comprometido con el acceso a un espacio social diverso y común. Lo cual exige también atención a las emociones, especialmente la compasión. De ahí que proponga formar un ethos profesional desde la razón cordial, una razón humana que integra habilidades y conocimientos con las razones del corazón. Su propuesta de formación universitaria se concreta, pues, en la formación de un ethos profesional razonable y cordial que permita contar con profesionales responsables en la 
solución de los problemas sociales. La adquisición de este ethos a través de una adecuada formación universitaria resulta necesaria porque constituye una obligación moral proteger y empoderar a las personas con diversidad funcional (Cortina, 2009b: I 88 y 225), en virtud de que son seres humanos con igual dignidad. Puede decirse, pues, que la accesibilidad universal, en tanto que proporciona a tales personas iguales condiciones de acceso a sus derechos, contribuye a que la comunidad civil y política reconozca a tales personas y les facilite institucionalmente ${ }^{\mathrm{Io}}$ su inclusión en la misma, concretando así dicha obligación moral.

Un planteamiento con bastantes similitudes lo encontramos en el enfoque de las capacidades desarrollado por Martha Nussbaum. La filósofa norteamericana rechaza una concepción de la ciudadanía basada en el mito de la perfección corporal y justifica que el trato que debe darse a las personas con diversidad funcional constituye un asunto de justicia (Nussbaum, 2007). A su juicio, debe construirse una comunidad política que disponga de un entorno facilitador (2006: 364) para la inclusión de dichas personas. Desde este punto de vista, la accesibilidad universal respondería al igual derecho a ocupar el espacio público que tienen las personas con necesidades atípicas (2006: 35 I-353). En lo que respecta a su concepción de la educación universitaria (Nussbaum, 20I4) es partidaria de que los grupos sociales minoritarios sean objeto de conocimiento, lo que facilita a los futuros profesionales una formación sobre los problemas sociales que,

Io. Tales diseños institucionales (Cortina, 2009a: 222-223) -que afectarían a la institución universitaria, a las profesiones y a la sociedad política - han de estar basados en los principios básicos de la ética cordial, entre los que cabe destacar el principio de no dañar y el principio del empoderamiento. en tanto que ciudadanos del sistema democrático, tienen que intentar resolver. El modelo de educación liberal que propugna (20I4: 28-30) para la formación de profesionales compagina la formación técnica con una formación humanística centrada en tres pilares: a) adquisición de habilidades de reflexión crítica y de deliberación que permitan el ejercicio de una ciudadanía democrática; b) el fomento de la capacidad moral de vincularnos con otros grupos humanos y responsabilizarnos de ellos, pese a las diferencias que actualmente puedan existir entre sus vidas y las nuestras y c) la adquisición de destrezas imaginativas que permitan el desarrollo de la empatía y la compasión, necesarias para dar un trato justo a todas las personas (20I4:I26). Así pues, el modelo de educación universitaria defendido por Nussbaum, en el que deben formarse los futuros profesionales que se ocuparán de los diseños conducentes a la accesibilidad universal, también va más allá de la mera formación técnica. Esta pensadora también propugna una formación en capacidades morales que posibiliten el reconocimiento de las demás personas y la justicia en el trato que debe darse a las necesidades de todos los ciudadanos.

b. En su obra Neuroética y neuropolítica la profesora Cortina aborda la misma temática de la educación moral, en sentido amplio, pero ahora teniendo en cuenta las aportaciones de las neurociencias ${ }^{\mathrm{II}}$. La educación de la persona no puede quedar al margen de cómo funciona el cerebro, en tanto que es el órgano en el que residen las capacidades racionales y emocionales del educando, y cómo debería ser orientado. De ahí que su propuesta de educación desde la razón cordial integre dos aspectos

I I. Una reciente aplicación de tales ideas, si bien limitada al ámbito de la educación secundaria, es la propuesta de $\mathrm{M}^{\mathrm{a}}$ José Codina (2015). 
que tradicionalmente se consideraba que estaban separados:

I. Educar en la razón: la educación no puede confundirse con la indoctrinación, con un saber dogmáticamente transmitido, alérgico a toda deliberación. El ethos profesional que debe fomentar la educación superior habrá de ser, en consecuencia, un ethos crítico y dialogante ${ }^{12}$. Esto exige que se fomente el desarrollo de la capacidad argumentativa, la cual habrá de utilizarse para enjuiciar moralmente los problemas sociales analizados, buscando determinar una justa solución.

Su planteamiento dialógico-cordial ${ }^{13}$ implica que se dispone de un canon crítico para determinar la justicia de la solución dada a un problema social: una solución será justa cuando, en el diálogo racional en que puedan haber participado todos los afectados en condiciones de simetría, se respeten sus derechos pragmáticos (por ejemplo, que ningún afectado sea excluido del mismo, que pueda aportar las razones que estime convenientes sin estar coaccionado externamente, que cualquier participante pueda criticar las razones aportadas, etc.) y la solución que se adopte esté basada en la fuerza del mejor

I2. También coincide Martha Nussbaum (2006) en este aspecto cuando propone el ideal liberal de educación superior que responda a un ethos socrático, en el sentido de que rechace la autoridad de la tradición y deje únicamente en pie aquellas creencias y prácticas que superen el escrutinio del razonamiento lógico y del juicio crítico.

I3. Dicho planteamiento ético constituye una versión cálida de la ética del diálogo de K. O. Apel y J. Habermas, la cual constituye una versión lógico-procedimental de la justicia.

Mientras estos autores se centran en la racionalidad dialógica, excluyendo el ámbito emocional, la ética cordial entiende que una razón íntegramente humana es una razón en el cuerpo.

De ahí que las emociones - como la compasión -, originadas corporalmente, resulten necesarias para el reconocimiento de todas las personas - incluidas las personas con diversidad funcional - y para la búsqueda de un diálogo racional con la finalidad de argumentar acerca de lo que es justo (Cortina, 2009a). argumento aportado, de forma que todos los participantes podrían dar su consentimiento a las conclusiones. No obstante, hay que matizar que no cabría someter el mismo derecho a la accesibilidad universal a un diálogo racional que decidiera si debe adoptarse o no. Y ello porque (Cortina, 20Io: I I2-I I6) entiende que los derechos humanos quedan fundamentados porque constituyen condiciones de posibilidad para el diálogo racional. Sin la protección de los derechos humanos - entre los cuales está la accesibilidad universalno quedarían protegidos aquellos afectados por las normas que han de poder participar en el diálogo y, entonces, el diálogo perdería su sentido. Lo que sí debe hacerse en todo caso es someter a un diálogo racional - en el que se debe incluir a las propias personas con diversidad funcional como interlocutores válidos - aquellos diseños que se presenten como normas opcionales que concretan la accesibilidad universal. Se tratará de determinar si una opción diseñada es o no justa.

2. Educar en la emoción: a juicio de la profesora Cortina, no basta con educar en la razonabilidad, en una razón que es dialógica. El cerebro tiene una dimensión emocional ${ }^{14}$ que también ha de ser tenida en cuenta en la formación del ethos profesional. En tal sentido, propone educar en la formación de un ethos profesional compasivo, en la medida en que la compasión con la vulnerabilidad humana - física y

I4. También Martha C. Nussbaum pone de manifiesto la importancia moral-política que tienen las emociones. Para esta autora (2013) una educación que fomente emociones positivas (compasión, respeto a todas las personas) y que frene emociones negativas (vergüenza) que influyen en la estigmatización de las personas con diversidad funcional, resulta necesaria porque contribuye a dar estabilidad a una sociedad justa. Desde este punto de vista, la educación emocional es la que facilitaría que los ciudadanos diesen un apoyo motivado al desarrollo de políticas públicas orientadas al mantenimiento y potenciación de la accesibilidad universal. 
social- es lo que impulsará a buscar la justicia acerca de las normas reguladoras de la accesibilidad universal en las diferentes profesiones. Este ethos compasivo es el que permite verdaderamente - poniéndose en lugar del otro y sintiendo como élque el profesional comprenda las circunstancias en que se encuentra la persona con diversidad funcional, en tanto que usuaria de su servicio y, al mismo tiempo, es el que le hace apreciar el valor de su dignidad.

Así pues, la educación universitaria, para forjar el carácter de los profesionales de modo que puedan afrontar las tareas que tendrán encomendadas para la realización de diseños que fomenten un espacio social accesible, tendrá que basarse en la adquisición de conocimientos técnicoestratégicos de la propia especialidad y conocimientos sobre los grupos de usuarios; también en la adquisición de habilidades de pensamiento crítico y de argumentación racional, sin olvidar la necesidad de incorporar también una adecuada competencia emocional que permita al profesional comprender las circunstancias en que se desenvuelve la vida del usuario, apreciar el valor de su dignidad y llegar a tratarlo con un respeto activo y empático.

Comenta la profesora Cortina (20I I: 236) que "una sociedad que quiera apostar por el cuidado de la dignidad humana debería hacerla transpirable en la vida cotidiana". Puede añadirse que uno de los aspectos en que puede incorporarse este cuidado es construyendo un mundo accesible para todas las personas, porque todas tienen igual dignidad. La formación universitaria de los profesionales de los diferentes campos ha de contribuir a ir consiguiéndolo.

\section{Conclusiones}

El compromiso fundamental que tienen las profesiones es aquel que liga al profesional “a las personas concretas" (Cortina, 2005a: I6I). La accesibilidad universal constituye un compromiso ético de las profesiones con las personas concretas, teniendo en cuenta que vivimos en una sociedad pluralista en la que se producen demandas de justicia para atender a la diferencia. En tal contexto, es necesario contar con profesionales que desarrollen un ethos que favorezca un servicio profesional auténticamente universal, atento a la diversidad humana y que ofrezca diseños versátiles y ampliamente empoderantes, con el fin de atender al amplio espectro de necesidades humanas existentes.

De modo correlativo, la responsabilidad social de la universidad, en tanto que formadora de profesionales especializados que puedan realizar diseños que busquen solucionar esta problemática social, se concreta, parcialmente, en la realización del compromiso de transformación del espacio formativo para impulsar una sociedad accesible. Para tener éxito en esta tarea sería conveniente que se aportara una formación moral en sentido amplio, en la que se produzca la confluencia de unas habilidades técnicas empleadas con diligencia, el desarrollo de la prudencia y la estimulación del sentido de justicia y la gratuidad. Se trata de formar profesionales conscientes de su responsabilidad con los ciudadanos y con la humanidad, de configurar un ethos profesional consciente de la diversidad humana, que se oriente al reconocimiento de la dignidad de todas las personas y de los derechos humanos, para cumplir el compromiso de construir un mundo accesible para todas las personas. Una tarea compleja y valiosa de la que los profesionales - al igual que el resto de los seres humanos - son corresponsables. 


\section{Referencias bibliográficas}

Arjona Jiménez, G. (2015): La accesibilidad y el diseño universal entendido por todos. De cómo Stephen Hawking viajó por el espacio. Granada: La Ciudad Accesible.

Bariffi, F. et al. (2008): La accesibilidad universal en los medios audiovisuales de comunicación. Madrid: Real Patronato sobre Discapacidad.

Codina, M. J. (201 5): Neuroeducación en virtudes cordiales: cómo reconciliar lo que decimos con lo que hacemos. Barcelona: Octaedro.

Cortina, A. (2016): Ética para una universidad cosmopolita (en línea). <http://www.um.es/ web/universidad/doctores-honoris-causa/adelacortina>, acceso I9 de mayo de 2017.

Cortina, A. (20I I): Neuroética y neuropolitica. Sugerencias para la educación moral. Madrid: Tecnos.

Cortina, A. (2010): Justicia cordial. Madrid: Trotta.

Cortina, A. (2009a): Ética de la razón cordial. Oviedo: Ediciones Nobel.

Cortina, A. (2009b): Las fronteras de la persona. Madrid, Taurus.

Cortina, A. (2005a): Ciudadanos del mundo. Hacia una teoría de la ciudadanía. Madrid: Alianza Editorial.

Cortina, A. (2005b): Ética de la empresa. Claves para una nueva cultura empresarial. Madrid: Trotta.

Cortina, A. (2005c): Alianza y Contrato. Madrid: Trotta.

CRUE y Fundación ONCE (2OI4): Formación curricular en diseño para todas las personas en Derecho. Madrid: CRUE.

De Asís, R. (2013): Sobre la accesibilidad universal (en línea). <http://portal.uc3m.es/portal/ page/portal/instituto_derechos_humanos/ conferencia_cdpd/Ponencias/rafael_asis_mesa4. pdf>, acceso I9 de mayo de 2017.
España. Ley 49/2007, de 26 de diciembre, por la que se establece el régimen de infracciones y sanciones en materia de igualdad de oportunidades, no discriminación y accesibilidad universal de las personas con discapacidad, Boletín Oficial del Estado, 27 de diciembre de 2007, núm. 3 IO, pp. 53278- 53284 .

España. Real Decreto I393/2007, de 29 de octubre, por el que se establece la ordenación de las enseñanzas universitarias oficiales, Boletín Oficial del Estado, 30 de octubre de 2007, núm. 260, pp. I-28.

España. Ley 51/2003, de 2 de diciembre, de igualdad de oportunidades, no discriminación y accesibilidad universal de las personas con discapacidad, Boletín Oficial del Estado, 3 de diciembre de 2003, núm. 289, pp. I-I8.

Etxeberria, X. (2008): La condición de ciudadanía de las personas con discapacidad intelectual. Bilbao: Universidad de Deusto.

Etxeberria, X. (2005): Aproximación ética a la discapacidad. Bilbao: Universidad de Deusto.

Gómez-Senent, E. (2000): “Ingeniería”, en Cortina, A. y Conill, J. (dirs.): Io palabras clave en ética de las profesiones. Estella, Navarra: Editorial Verbo Divino.

Habermas, J. (2008): La inclusión del otro. Barcelona: Paidós.

Habermas, J. (2000): "Del uso pragmático, ético y moral de la razón práctica”, en Habermas, J.: Aclaraciones a la ética del discurso. Madrid: Trotta: I09-I26.

Honneth, A. (2014): El derecho de la libertad. Esbozo de una eticidad democrática. Madrid: Katz.

Honneth, A. (2006): "Redistribución como reconocimiento", en Fraser, N. y Honneth, A.: ¿Redistribución o reconocimiento?. Madrid: Morata.

Hortal, A. (2002): Ética general de las profesiones. Bilbao: Desclée de Brouwer. 
Kant, I. (I980): Fundamentación de la Metafísica de las costumbres. México, D.F.: Porrúa.

Lozano, J. F. (20I I): Qué es la ética de la empresa. Cànoves y Samalús: Proteus.

Martínez Navarro, E. (20I4): "El compromiso ético y político del ejercicio profesional: servicio diligente y denuncia de la injusticia”, en Luján, I. et al. (eds.): Pensamiento crítico y diálogo fe-cultura. Homenaje a Pepe Alonso. Universidad de las Palmas de Gran Canaria.

Martínez Navarro, E. (2010): Ética profesional de los profesores. Bilbao: Desclée de Brouwer.

Martínez Navarro, E. (2006): "Ética de la profesión: proyecto personal y compromiso de ciudadanía”. Veritas, I4: I2I-I39.

Nussbaum, M. (20I4): El cultivo de la humanidad. Una defensa clásica de la reforma en la educación liberal. Barcelona: Paidós.

Nussbaum, M. (20I3): Emociones politicas. Barcelona: Paidós.

Nussbaum, M. (2007): Las fronteras de la justicia. Barcelona: Paidós.

Nussbaum, M. (2006): El ocultamiento de lo humano: repugnancia, vergüenza y ley. Madrid: Katz.
Observatorio Universidad y Discapacidad (2OI2): La Responsabilidad Social Universitaria (RSU-D). Vilanova i la Geltrú, Barcelona: Fundación ONCE y Universidad Politécnica de Cataluña.

ONU (2006): Convención sobre los Derechos de las Personas con Discapacidad (en línea). <http:// www.un.org/esa/socdev/enable/documents/ tccconvs.pdf>, acceso 27 de diciembre de 2016 .

Ortega, P. (20I0): "Educar es responder a la pregunta del otro". Edetania, 37: I3-3 I.

Palacios, A. (2008): El modelo social de la discapacidad: orígenes, caracterización y plasmación en la Convención Internacional sobre los Derechos de las Personas con Discapacidad. Madrid: Ediciones Cinca.

Quintanilla, M. A. (I995): "La construcción del futuro", en Broncano, F. (ed.): Nuevas meditaciones sobre la técnica. Madrid: Trotta.

Rescher, N. (I999): Razón y valores en la era científico-tecnológica. Barcelona: Paidós/I.C.E. de la Universidad Autónoma de Barcelona.

Vallaeys, F. et al. (2009): Responsabilidad Social Universitaria. Manual de primeros pasos. México D. F.: Banco Interamericano de Desarrollo/ Mc Graw-Hill. 